\title{
Barium Dichloride as a Powerful and Inexpensive Catalyst for the Pechmann Condensation without Using Solvent
}

\author{
Saeed Khodabakhshi \\ Department of Chemistry, Islamic Azad University, Gachsaran Branch, Gachsaran, Iran \\ Correspondence should be addressed to Saeed Khodabakhshi, saeidkhm@yahoo.com \\ Received 17 August 2012; Revised 2 October 2012; Accepted 2 October 2012 \\ Academic Editor: Robert Engel
}

Copyright ( $) 2012$ Saeed Khodabakhshi. This is an open access article distributed under the Creative Commons Attribution License, which permits unrestricted use, distribution, and reproduction in any medium, provided the original work is properly cited.

Various coumarin derivatives have been efficiently synthesized via barium dichloride-catalyzed Pechmann condensation reaction of various phenols and $\beta$-keto esters under solvent-free conditions. This novel and inexpensive method has advantages such as short reaction times, excellent product yields, and avoidance of organic solvents in agreement with green chemistry principles.

\section{Introduction}

The development of procedures to prepare heterocycles is of vital importance in synthesis of organic compounds, especially the heterocycles which can be found in naturally occurring products [1]. Coumarin derivatives possess diverse biological properties. For example, some polycyclic coumarins such as calanolides [2] isolated from Calophyllum genus, and others have shown potent anti-HIV activity [3]. Numerous coumarins have been also used as drug in contemporary medicine. As can be seen in Figure 1, warfarin, acenocoumarol, and phenprocoumon are vitamin $\mathrm{K}$ antagonists which play an anticoagulant role in the treatment of thromboembolic disorders [4].

Besides, some coumarins are used as additives in food and cosmetics [5], optical brighteners [6], and dispersed fluorescent and laser dyes [7]. Due to the abovementioned properties of these heterocycles, their synthesis has attracted much attention of researchers. Coumarins have been synthesized by several methods. Some of them suffer from disadvantages such as harsh conditions, long reaction times, low yield of products, and use of expensive and toxic reagents or organic solvents [8-12]. In continuation of our study on catalyzed reactions [13], in this paper, a new application of barium dichloride as a Lewis acid catalyst in the synthesis of some coumarins is reported.

\section{Results and Discussion}

Establishing the reaction based on solvent-free conditions obviously reduces pollution and brings down handling costs due to simplification of experimental procedure, workup technique, and saving in labour [14].

In 1883, Pechmann and Duisberg found that phenols condense with $\beta$-ketonic esters in the presence of sulfuric acid, giving coumarin (benzo-2-pyrone) derivatives [15]. In fact, Pechmann condensation is a commonly method for the preparation of coumarin derivatives because it proceeds from simple precursor such as phenols and $\beta$-ketoesters. However, via the Pechmann condensation, coumarins with substitution on either pyrone or benzene ring or both are affordable in good-to-excellent yield. In this study, we found that the Pechmann cyclocondensation of phenols $\mathbf{1}$ with $\beta$-ketoesters 2 in the presence of barium dichloride as an efficient catalyst produces the substituted coumarins $\mathbf{3}$ under thermal and solvent-free conditions (Scheme 1).

In order to optimize the reaction conditions, we tested both various temperatures and amounts of the catalyst $\left(\mathrm{BaCl}_{2}\right)$ in the reaction of phloroglucinol (1a) with ethyl acetoacetate (2a) as a model reaction to investigate the effects of catalyst amount and temperature for the preparation of 5,7-dihydroxy-4-methylcoumarin (3a) (Scheme 2).

As shown in Tables 1 and 2, it can be concluded that the thermal-assisted model reaction is efficiently carried out by 


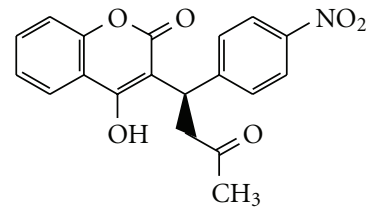

Acenocoumarol

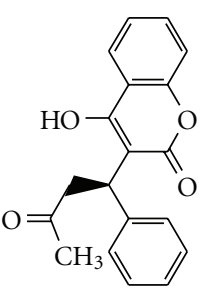

Warfarin

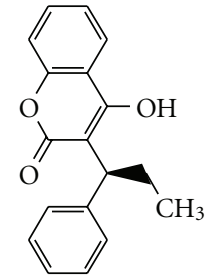

Phenprocoumon

FIgURE 1: Chemical structure of some biologically active coumarins.

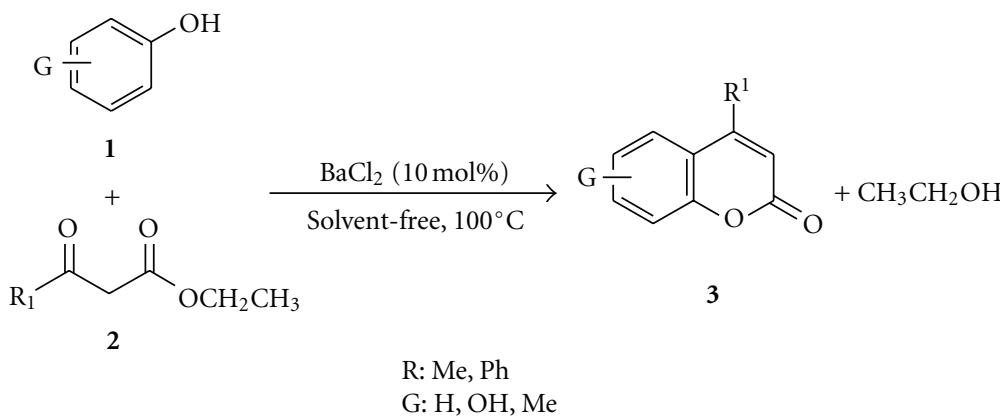

Scheme 1: The Pechmann reaction catalyzed by barium dichloride.<smiles>CCOC(=O)CC(C)=O</smiles>

Scheme 2: The reaction of phloroglucinol and ethyl acetoacetate under various conditions.

TABLE 1: The effect of catalyst amount on the synthesis of $\mathbf{3 a}$ at $100^{\circ} \mathrm{C}$ under solvent-free conditions.

\begin{tabular}{lccc}
\hline Entry & Catalyst $(\mathrm{mol} \%)$ & Time $(\mathrm{min})$ & Yield $^{\mathrm{a}}(\%)$ \\
\hline 1 & - & 25 & Trace \\
2 & 2 & 25 & 25 \\
3 & 5 & 25 & 40 \\
4 & 7 & 25 & 75 \\
5 & 10 & 25 & 90 \\
6 & 20 & 25 & 85 \\
\hline
\end{tabular}

${ }^{a}$ Refers to isolated yields.

adding catalytic amounts of barium dichloride (10 mol\%) in solventless conditions at $100^{\circ} \mathrm{C}$. The excessive amounts of catalyst or higher temperature than $100^{\circ} \mathrm{C}$ cannot improve the product yield.

After optimization of the reaction conditions, as can be seen in Table 3 , in order to extend the scope of this reaction, various phenols such as resorcinol, pyrogallol, and phloroglucinol were successfully used for the efficient Pechmann reaction with different $\beta$-ketoesters. A wide variety of coumarins were obtained through this method in good-to-excellent yield in short reaction times (Table 2).
TABLE 2: The effect of temperature on the synthesis of $3 \mathbf{a}$ using $\mathrm{BaCl}_{2}(10 \mathrm{~mol} \%)$ under solvent-free conditions.

\begin{tabular}{lccc}
\hline Entry & Temperature $\left({ }^{\circ} \mathrm{C}\right)$ & Time $(\mathrm{min})$ & Yield $^{\mathrm{a}}(\%)$ \\
\hline 1 & 25 & 25 & Trace \\
2 & 70 & 25 & 50 \\
3 & 100 & 25 & 90 \\
4 & 130 & 25 & 80 \\
\hline${ }^{a}$ Refers to isolated yields.
\end{tabular}

The ${ }^{1} \mathrm{H}$ NMR spectrum of $\mathbf{3 a}$ exhibited five sharp singlets identified as methyl $(\delta=2.49 \mathrm{ppm})$, olefinic pyrone $\operatorname{ring}(\delta=$ $5.83 \mathrm{ppm})$, two $\mathrm{OH}$ groups $(\delta=10.28,10.51 \mathrm{ppm})$, and protons. Two singlet signals $(\delta=6.15 \mathrm{ppm})$ and $(\delta=6.24 \mathrm{ppm})$ correspond to the aromatic protons of benzene ring. The proton-decoupled ${ }^{13} \mathrm{C}$ NMR spectrum of $3 \mathbf{a}$ showed 10 distinct resonances in agreement with the proposed structure. A reasonable mechanism for barium-catalyzed Pechmann reaction has been proposed in Scheme 3.

In summary, the presented report demonstrates facile barium dichloride-catalyzed synthesis of coumarins via the Pechmann reactions. The important advantages of this method are the short reaction time, high yields, simple 
TABle 3: Synthesis of some coumarin derivatives based on Pechmann condensation using barium dichloride at $100^{\circ} \mathrm{C}$ under solvent-free conditions.

\begin{tabular}{|c|c|c|c|c|}
\hline Entry & Product $^{\mathrm{a}}$ & Time (min) & Yield $^{\mathrm{b}}(\%)$ & M.p. ${ }^{\circ} \mathrm{C}$ \\
\hline $3 a$ & & 25 & 90 & $288-290$ \\
\hline $3 b$ & & 35 & 85 & $188-190$ \\
\hline $3 c$ & & 30 & 85 & $243-245$ \\
\hline $3 d$ & & 30 & 90 & $244-246$ \\
\hline $3 e$ & & 55 & 80 & $257-259$ \\
\hline $3 f$ & & 50 & 85 & $243-245$ \\
\hline $3 g$ & & 40 & 90 & $150-152$ \\
\hline
\end{tabular}

${ }^{\mathrm{a}}$ Identified by comparison with authentic samples and their spectral data. ${ }^{\mathrm{b}}$ Refers to isolated yields.

workup, the use of inexpensive and available catalyst, the nonchromatographic purification of products, that is, simple recrystallization from $\mathrm{EtOH}$, and use of solvent-free conditions instead of organic solvents in accord with green chemistry criteria.

\section{Experimental Section}

3.1. General. The chemicals were purchased from Merck, Fluka, and Aldrich chemical companies. The reactions were monitored by TLC (silica-gel $60 \mathrm{~F}_{254}$, hexane: EtOAc). IR spectra were recorded on a FT-IR Shimadzu-470 spectrometer and the ${ }^{1} \mathrm{H}$ NMR spectra were obtained on a BrukerInstrument DPX-400 and 500 Avance 2 model.
3.2. General Procedure for the Preparation of Coumarin 3. A mixture of phenol 1 ( $1 \mathrm{mmol}), \beta$-ketoesters 2 ( $1 \mathrm{mmol})$, and barium dichloride $(10 \mathrm{~mol} \%)$ was heated and stirred at $100^{\circ} \mathrm{C}$. After completion of the reaction (controlled by TLC), the reaction mixture was cooled at room temperature and poured onto crushed ice. The solid product obtained was filtered off, washed with ice-cold water, and recrystallized from hot $\mathrm{EtOH}$ to obtain the pure product 3 .

Compound 3a. ${ }^{1} \mathrm{H}$ NMR (400 MHz, DMSO- $\left.d_{6}\right): \delta 10.51(\mathrm{~s}$, $1 \mathrm{H}), 10.28(\mathrm{~s}, 1 \mathrm{H}), 6.24(\mathrm{~s}, 1 \mathrm{H}), 6.15(\mathrm{~s}, 1 \mathrm{H}), 5.83(\mathrm{~s}, 1 \mathrm{H})$, $2.47(\mathrm{~s}, 3 \mathrm{H}) .{ }^{13} \mathrm{C} \mathrm{NMR}\left(100 \mathrm{MHz}, \mathrm{DMSO}-d_{6}\right): \delta 161.51$, $160.55,158.39,155.43,109.29,102.55,99.54,94.98,23.88$. Anal. Calcd. For $\mathrm{C}_{10} \mathrm{H}_{8} \mathrm{O}_{4}$ : C, 62.50; H, 4.20. Found: C, 62.69, $\mathrm{H}, 4.15$. 


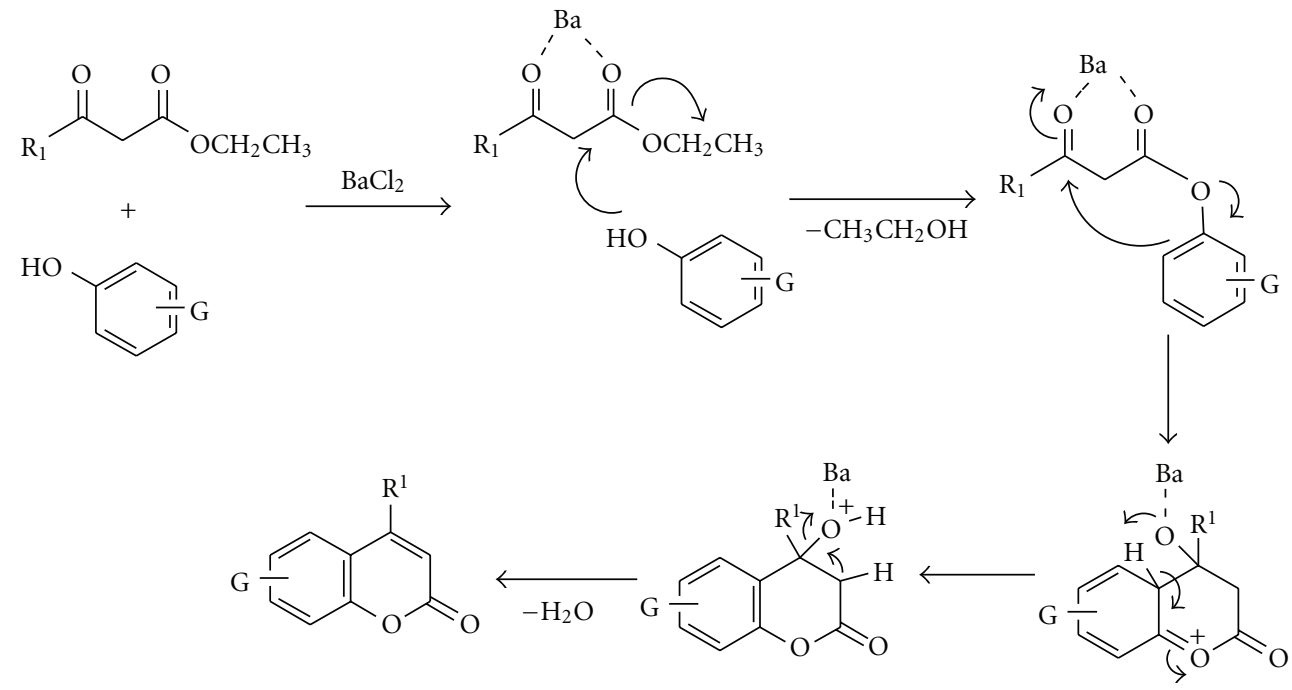

Scheme 3: Suggested mechanism for the Pechmann reaction catalyzed by barium dichloride.

Compound 3b. ${ }^{1} \mathrm{H}$ NMR $\left(500 \mathrm{MHz}, \mathrm{CDCl}_{3}\right): \delta 7.49-7.47(\mathrm{~d}$, $J=6.8 \mathrm{~Hz}), 6.85(\mathrm{~d}, 1 \mathrm{H}, J=2 \mathrm{~Hz}), 6.82(\mathrm{dd}, 1 \mathrm{H}, J=6.8$, $2.4 \mathrm{~Hz}), 6.14(\mathrm{~s}, 1 \mathrm{H}), 5.7(\mathrm{~s}, 1 \mathrm{H}), 2.35$ (s, 3H). Anal. Calcd. For $\mathrm{C}_{10} \mathrm{H}_{8} \mathrm{O}_{3}$ : C, 68.18; H, 4.58. Found: C, 68.36, H, 4.50 .

Compound 3c. ${ }^{1} \mathrm{H}$ NMR (400 MHz, DMSO- $\left.d_{6}\right): \delta 10.15(\mathrm{~s}$, $1 \mathrm{H}), 9.30(\mathrm{~s}, 1 \mathrm{H}), 7.08(\mathrm{~d}, 1 \mathrm{H}, J=8.8 \mathrm{~Hz}), 6.81(\mathrm{~d}, 1 \mathrm{H}$, $J=8.8 \mathrm{~Hz}), 6.10(\mathrm{~s}, 1 \mathrm{H}), 2.33(\mathrm{~s}, 3 \mathrm{H}) .{ }^{13} \mathrm{C} \mathrm{NMR}(100 \mathrm{MHz}$, DMSO- $\left.d_{6}\right): 160.47,154.35,149.81,144.13,143.74,132.60$, $115.88,113.23,112.56,110.60,40.42,40.21,40.00,39.79$, 39.58, 39.38, 39.17, 18.63. Anal. Calcd. For $\mathrm{C}_{10} \mathrm{H}_{8} \mathrm{O}_{4}$ : C, 62.50; H, 4.20. Found: C, 62.58, H, 4.27.

Compound 3d. ${ }^{1} \mathrm{H}$ NMR (400 MHz, DMSO- $\left.d_{6}\right): \delta 10.52(\mathrm{~s}$, $1 \mathrm{H}), 6.60(\mathrm{~d}, 2 \mathrm{H}), 6.03(\mathrm{~s}, 1 \mathrm{H}), 3.49(\mathrm{~s}, 3 \mathrm{H}), 2.26(\mathrm{~s}, 3 \mathrm{H}) .{ }^{13} \mathrm{C}$ NMR (100 MHz, DMSO- $\left.d_{6}\right)$ : 160.29, 156.90, 155.28, 155.04, 143.18, 112.37, 112.30, 108.15, 106.96, 23.91, 21.56. Anal. Calcd. For $\mathrm{C}_{11} \mathrm{H}_{10} \mathrm{O}_{3}$ : C, 69.46; H, 5.30. Found: C, 69.71, H, 5.25 .

Compound 3e. ${ }^{1} \mathrm{H}$ NMR (400 MHz, DMSO- $\left.d_{6}\right): \delta 10.65(\mathrm{~s}$, $1 \mathrm{H}), 7.34(\mathrm{~s}, 4 \mathrm{H}), 7.28,(\mathrm{~s}, 2 \mathrm{H}), 7.05(\mathrm{~d}, 1 \mathrm{H}, J=8.8 \mathrm{~Hz}), 6.56$ $(\mathrm{m}, 2 \mathrm{H}) .{ }^{13} \mathrm{C}$ NMR $\left(100 \mathrm{MHz}, \mathrm{DMSO}-d_{6}\right): 161.80,160.77$, $155.96,135.52,130.07,129.29,128.79,128.54,113.68$, 111.08, 110.70. Anal. Calcd. For $\mathrm{C}_{15} \mathrm{H}_{10} \mathrm{O}_{3}$ : C, 75.62; H, 4.23. Found: C, 75.88, H, 4.18.

Compound 3f. ${ }^{1} \mathrm{H}$ NMR (400 MHz, DMSO-d 6 ): $\delta 10.13$ $(\mathrm{s}, 1 \mathrm{H}), 7.37(\mathrm{~m}, 5 \mathrm{H}), 6.72(\mathrm{~s}, 1 \mathrm{H}), 6.47(\mathrm{~s}, 1 \mathrm{H}), 5.95(\mathrm{~s}$, $1 \mathrm{H}), 2.29$ (s, 3H). ${ }^{13} \mathrm{C}$ NMR (100 MHz, DMSO- $\left.d_{6}\right): 160.09$, $156.05,155.96,155.91,143.93,139.75,128.34,127.92$, $127.75,113.88,112.52,108.19,105.44,21.65$. Anal. Calcd. For $\mathrm{C}_{16} \mathrm{H}_{12} \mathrm{O}_{3}$ : C, 76.18; H, 4.79. Found: C, 76.25, H, 4.82 .

Compound 3g. ${ }^{1} \mathrm{H}$ NMR (400 MHz, DMSO- $\left.d_{6}\right): \delta 7.96(\mathrm{~s}$, $1 \mathrm{H}), 6.97(\mathrm{~s}, 2 \mathrm{H}), 6.20(\mathrm{~s}, 1 \mathrm{H}), 3.85(\mathrm{~s}, 3 \mathrm{H}), 2.39(\mathrm{~s}, 3 \mathrm{H})$.

${ }^{13} \mathrm{C}$ NMR $\left(100 \mathrm{MHz}, \mathrm{DMSO}-d_{6}\right): \delta 162.83,160.59,155.24$,
153.86, 126.88, 113.66, 112.54, 111.58, 101.16, 56.36, 18.58. Anal. Calcd. For $\mathrm{C}_{11} \mathrm{H}_{10} \mathrm{O}_{3}$ : C, 69.46; H, 5.30. Found: C, 69.70, H, 4.17.

\section{Acknowledgment}

The author gratefully acknowledges the partial support of this work by the Islamic Azad University, Gachsaran Branch, Iran.

\section{References}

[1] P. K. Basu and A. Ghosh, "Microwave-assisted improved regioselective synthesis of $12 \mathrm{H}$-benzopyrano[3, 2-c] [1] benzopyran-5-ones by radical cyclisation," Organic Chemistry International, vol. 2011, Article ID 394619, 6 pages, 2011.

[2] Y. Kashman, K. R. Gustafson, R. W. Fuller et al., "HIV inhibitory natural products. Part 7. The calanolides, a novel HIV-inhibitory class of coumarin derivatives from the tropical rainforest tree, Calophyllum lanigerum," Journal of Medicinal Chemistry, vol. 35, no. 15, pp. 2735-2743, 1992.

[3] A. Shockravi, H. Shargi, H. Valizadeh, and M. M. Heravi, "Solvent free synthesis of coumarins," Phosphorus, Sulfur and Silicon and the Related Elements, vol. 177, no. 11, pp. 25552559, 2002.

[4] M. Beinema, J. R. B. J. Brouwers, T. Schalekamp, and B. Wilffert, "Pharmacogenetic differences between warfarin, acenocoumarol and phenprocoumon," Thrombosis and Haemostasis, vol. 100, no. 6, pp. 1052-1057, 2008.

[5] R. O'Kennedy and R. D. Thornes, Coumarins: Biology, Applications, and Mode of Action, John Wiley \& Sons, Chichester, UK, 1997.

[6] M. Zahradnik, The Production and Application of Fluorescent Brightening Agents, John Wiley \& Sons, New York, NY, USA, 1992.

[7] R. D. H. Murray, J. Mendez, and S. A. Brown, The Natural Coumarins: Occurrence, Chemistry, and Biochemistry, John Wiley \& Sons, New York, NY, USA, 1982. 
[8] S. K. De and R. A. Gibbs, "An efficient and practical procedure for the synthesis of 4-substituted coumarins," Synthesis, no. 8, pp. 1231-1233, 2005.

[9] P. Goswami, "Dually activated organo- and nano-cocatalyzed synthesis of coumarin derivatives," Synthetic Communications, vol. 39, no. 13, pp. 2271-2278, 2009.

[10] Y. T. Reddy, V. N. Sonar, P. A. Crooks, P. K. Dasari, P. N. Reddy, and B. Rajitha, "Ceric ammonium nitrate (CAN): an efficient catalyst for the coumarin synthesis via Pechmann condensation using conventional heating and microwave irradiation," Synthetic Communications, vol. 38, no. 13, pp. 2082-2088, 2008.

[11] S.-R. Sheng, P.-G. Huang, Q. Wang, R. Huang, and X.L. Liu, "Novel traceless liquid-phase synthesis of coumarin derivatives on poly(ethylene glycol) support," Synthetic Communications, vol. 36, no. 21, pp. 3175-3181, 2006.

[12] V. Kumar, S. Tomar, R. Patel, A. Yousaf, V. S. Parmar, and S. V. Malhotra, " $\mathrm{FeCl}_{3}$-catalyzed Pechmann synthesis of coumarins in ionic liquids," Synthetic Communications, vol. 38, no. 15, pp. 2646-2654, 2008.

[13] F. Jafari and S. Khodabakhshi, " $\mathrm{Mg}(\mathrm{HSO} 4)_{2} / \mathrm{SiO}_{2}$ as a highly efficient catalyst for the green preparation of 2-aryl-1,3dioxalanes/dioxanes and linear acetals," Organic Chemistry International, vol. 2012, Article ID 475301, 2012.

[14] F. Jafari and S. Khodabakhshi, "A green method for the synthesis of 2-aryl-1,3-dioxalanes/dioxanes and linear acetals using silica supported magnesium hydrogen phosphate $\left(\mathrm{MgHPO}_{4} / \mathrm{SiO}_{2}\right)$," Der Chemica Sinica, vol. 3, no. 4, pp. 775779, 2012.

[15] H. V. Pechmann and C. Duisberg, "Uber die verbindungen der phenole mit acetessigather," Chemische Berichte, vol. 16, pp. 2119-2128, 1883. 


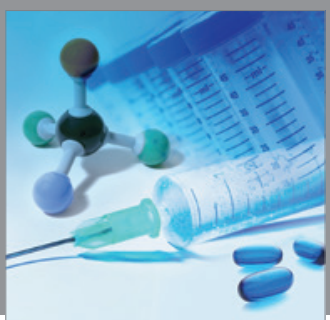

International Journal of

Medicinal Chemistry

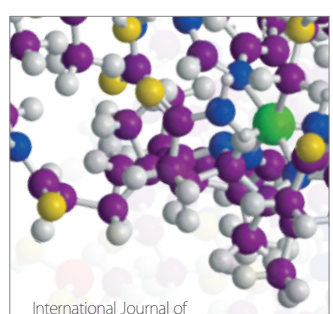

Carbohydrate Chemistry

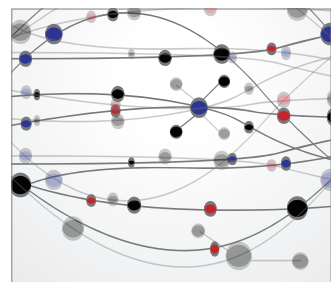

The Scientific World Journal
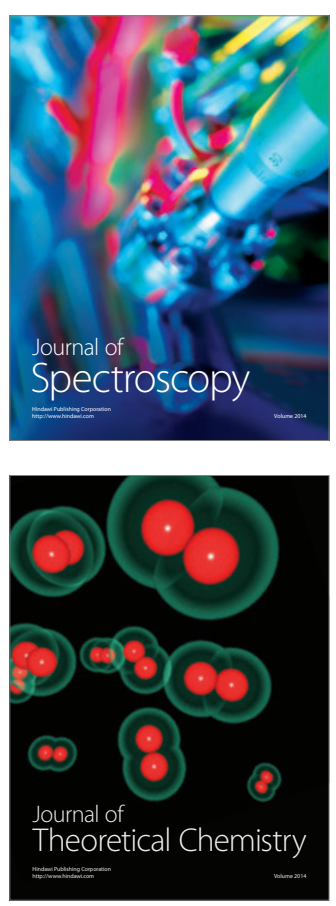
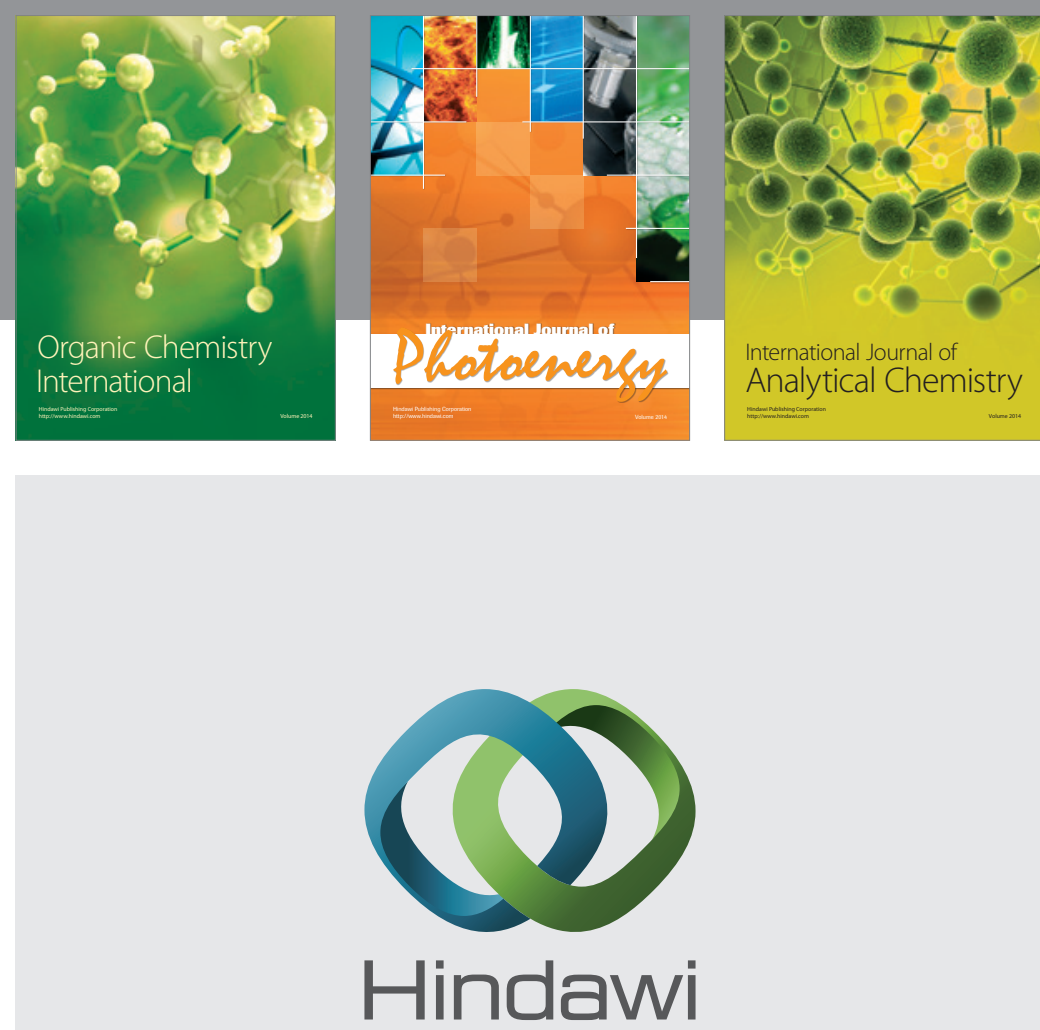

Submit your manuscripts at

http://www.hindawi.com
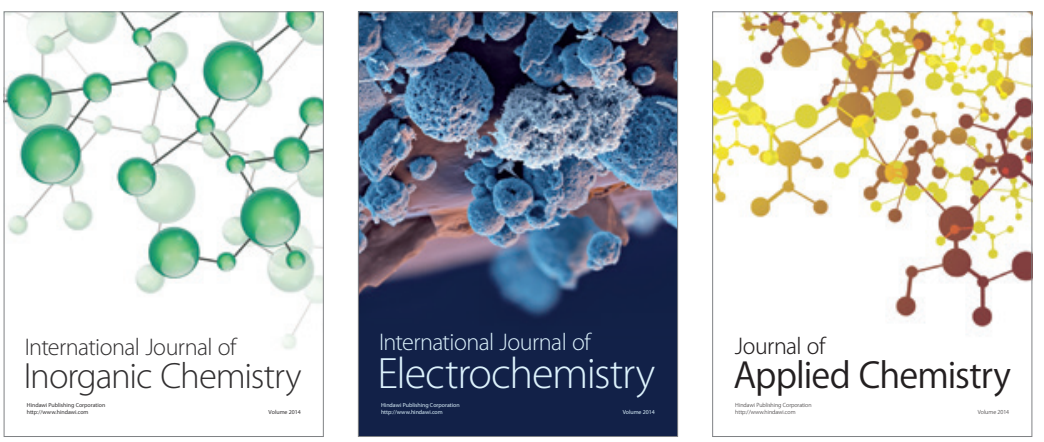

Journal of

Applied Chemistry
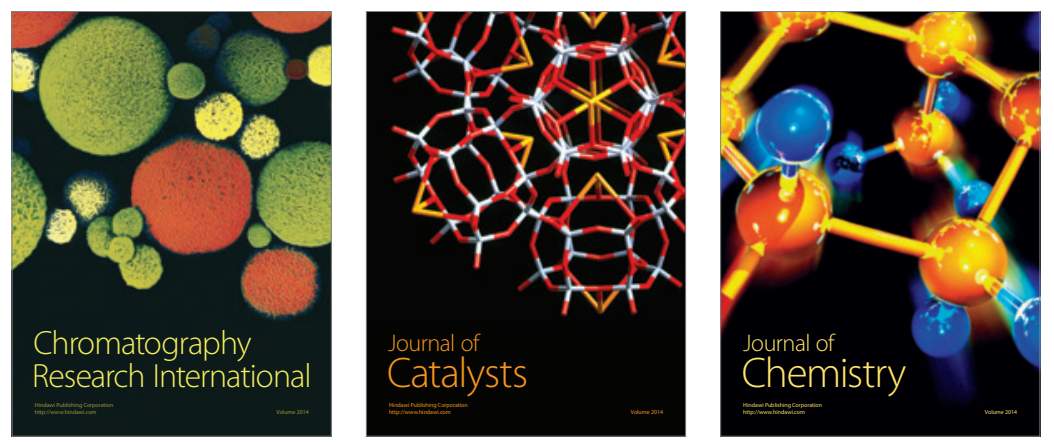
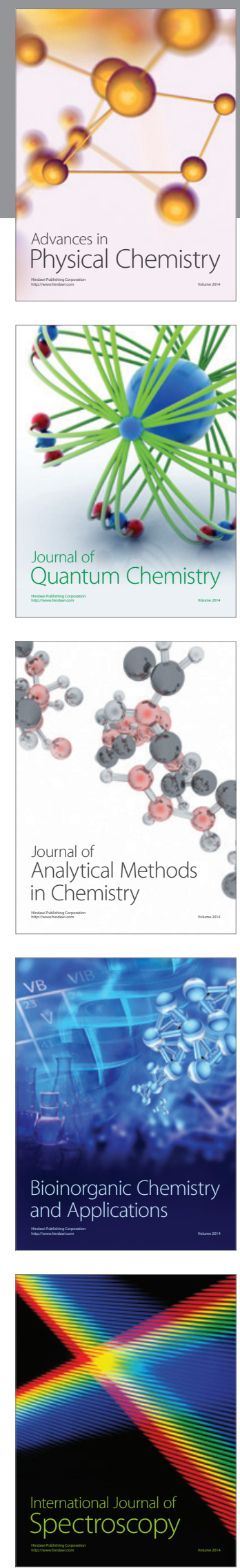